\title{
Comparison of Insects' Flight Characteristics with Observed Characteristics of Radar Dot Angels
}

\author{
M. S. Fowler and A. H. LAGrone \\ Anlennas and Propagation Laboratory, The University of Texas at Austin
}

(Manuscript received 10 September 1968, in revised form 14 November 1968)

\begin{abstract}
To assist the radar meteorologist in identifying certain types of echoes believed to originate with insects, the flying characteristics of insects have been obtained from entomologists' reports and compared with observed characteristics of dot angel type radar echoes. The entomologists' reports reveal that it does not appear likely one could predict the orientation of an insect in flight; consequently, polarization information obtained from dot angel echoes does not appear to be a useful bit of information in attempting to relate dot angels to insects. Reported insect flying speeds and flying altitudes are found to agree with measured speeds and altitudes of dot angel echoes. The endurance of insects in flight is found to be such that it can easily account for the time duration during which individual dot angels have been observed and for the time that would be required for insects to reach the altitude of the observed dot angels.
\end{abstract}

\section{Introduction}

Radar meteorologists are plagued with radar echoes from apparently clear skies that are not readily identifiable and which consequently interfere with atmospheric observations. One class of such targets is known as the "dot angel" and is believed by some to originate with insects. Characteristics of the dot angel type echo are well known to the radar meteorologist but the characteristics of flying insects at radar altitudes are not so well known. To reduce the problem created by insects, it would be helpful to be able to identify the dot angel as an insect if, indeed, such is the case.

Studies by the Antennas and Propagation Laboratory, The University of Texas at Austin (Hajovsky et al., 1966), have shown that insect radar cross sections are the proper order of magnitude, 0.01 to $10 \mathrm{~cm}^{2}$, to account for the observed dot angel type signals. The University of Texas study further showed a strong polarization dependence exhibited by insect radar cross sections. Insects with body lengths much greater than body diameters were found to have longitudinal and transverse cross sections which differed by as much as $15 \mathrm{db}$. More compact insects were found to have cross sections which differed by $7 \mathrm{db}$ or less. Longitudinal cross section refers to the $E$ field of the measuring radiation oriented parallel to the insect's body, while transverse cross section refers to the $E$ field oriented transverse to the insect's body.

Experiments performed jointly by the Air Force Cambridge Research Laboratories, the Applied Physics Laboratory of Johns Hopkins University, and the Entomology Research Division of the U. S. Department of Agriculture at Wallops Island, Va. (Glover et al., 1966), have shown conclusively that a single insect can be tracked by radar. If the orientation of the insect in flight were known or could be reliably predicted, the polarization dependence of its backscattering cross section would provide a means of helping to identify the insect as the source of the dot angel echo. As a result of this possibility, a study was made to see if the flight characteristics of insects could be predicted.

Entomologists' reports indicate that extensive research in the flying characteristics of insects has been conducted at altitudes far below those of radar target concern; however, the findings also indicate that the observed characteristics will remain the same at higher altitude. Entomologists have also found that most insects prefer to remain near the earth ; consequently, subjects at altitude are relatively few and scattered, although concentrations do exist.

\section{Flight orientation of insects}

Flight characteristics of mosquitoes (Diplera-Aëdes aegypti) were extensively studied by Kennedy (1940) with the aid of a wind tunnel. It was discovered that freely flying mosquitoes consistently flew upwind and maintained their position or made headway. When the wind speed was too strong to allow this, they were found to alight or to turn to fly downwind. Continued experimentation with a background of moving stripes indicated the characteristics to be optical response; that is, the upwind orientation was not an orientation to the wind itself but resulted from compensatory movements made in response to visual stimuli. Darkness abolished the effects, verifying that they were indeed the response to optical stimuli. The mosquitoes would not tolerate the passage of images across the retina from back to front nor would they allow lateral shifts. Any circumstances tending to create these conditions were compensated for by the insects. Further, they adjusted their 
flight speed so that the background image passed over their eyes at some constant rate. That is, they adjusted their air speed, according to the wind speed, to maintain constant ground speed. Thus, their ground speed was a function of the height at which they flew and the wind speed. Daykin (1967) studied the orientation of Aëdes aegypti to vertical currents in a wind tunnel and found the insects maintained a similar body attitude in updraft or downdraft.

In a tunnel in which the insects could rise no more than $0.1 \mathrm{~m}$ above the background, upwind orientation required a minimum wind speed of $0.1 \mathrm{~m} \mathrm{sec}^{-1}$ (Kennedy, 1940), their maximum ground speed being $0.3-0.4 \mathrm{~m} \mathrm{sec}^{-1}$. When the wind speed $>1.5 \mathrm{~m} \mathrm{sec}^{-1}$, the insects were forced to alight and would not take off because they could not maintain their positions in the tunnel. Kennedy supposed that at higher elevations even stronger winds would be required to orient the mosquitoes and that at some elevation, which he called the maximum compensatory height (Kennedy, 1951), no amount of wind could orient them. Since the responses are compensation for the apparent movement of the fixed substratum and since the farther the insects are from the ground, the lower the rate of apparent movement, it does follow that the orientation would be completely destroyed at some altitude far above ground. Either the pattern on the ground would be too small to see, or the speed of its image over the retina would be too slow to produce any optomotor response. Below the maximum compensatory height the insects would orient upwind. Above it, they would fly unhampered by the optical response and would be unaffected by the speed or direction of their displacement by wind relative to ground. They could fly to the limit of their capacity without exceeding the tolerated limit of retinal velocity. Kennedy did not specify this height for mosquitoes except to suggest that it was several meters.

Similar work with other insects is now also available. Markl and Lindauer (1965) cited work which claimed that flying insects, with the exception of flies (Diptera), bees (Hymenoptera-Apis), and dragonflies (Odonata), were found to drop down, spinning, when placed in a darkened room. [It is interesting that Hocking (1953) lists Diptera and Hymenoptera among the most efficient flying insects.] Hocking (1953) states that experimental studies of the influence of wind on orientation all indicate a strong tendency to fly into the wind for night flying butterflies and moths (Lepidoptera) and flies (Diptera). He does not state the heights of these experiments. Pruess and Pruess (1966) devised a directional trap to investigate flight orientations of insects less than a few meters above ground. Their results indicated that aphids (Homoptera-Aphidae) and leaf and plant bugs (Hemiptera-Miridae) were strongly oriented downwind, all Hymenoptera (insects such as bees, wasps, ants, parasites, gallflies, horntails and sawflies) appeared to fly upwind, and most Diptera (flies) had a slight tendency toward upwind flight. The results for
Hymenoptera were more pronounced on days with higher wind velocities. Activity was observed to decrease on such days.

In addition to the experimental indications, field observations also suggest a tendency of many insects to fly upwind. Evidence from studies of migration indicate a slight but definite tendency to fly into the wind on the part of butterflies (Lepidoptera) and a rather stronger tendency on the part of locusts (Orthoptera) (Hocking, 1953). According to Hocking, there is only one account of consistent downwind flights over a period of time where wind direction was varying, although there are many records of movement downwind which include no observations on flight direction. He further states that locusts have been observed to settle or to turn and fly with the wind when the wind speed was greater than flight speed in the upwind orientation, if the ground pattern was visible so that they would detect their backward movement relative to the ground.

Kennedy's results are applied to other insects as well as mosquitoes. Markl and Lindauer (1965) state that most insects react to a turn in the visual environment by optomotoric turning movements, whose direction and intensity keep the retinal shift of the surroundings at a minimum. Johnson (1965) says that when the wind is so strong that a locust is displaced backward or too fast laterally relative to the ground, while still maintaining a forward motion through the air, it is evidently its optomotor responses that cause it to turn and fly with the wind or to alight if possible. Hocking (1953) also attributes insect flight behavior to optomotor responses.

In discussing the flight of locusts, Johnson (1965) states that the insect perceives its own motion through the air with its aerodynamic sense organs located on the head and by sensing wind over its wings. In moving air, it must detect relative wind. The sense indicator acts as a directional air speed indicator and also stabilizes yawing by causing compensatory wing movements.

An insect flying in absolutely steady wind would not be able to determine the direction of the wind except by observing the movement of objects on the ground relative to its own direction of flight through the air (in the direction of its body axis) (Johnson, 1965). Such constant winds are not found in nature, but the structure of the normal wind with its eddies, as now recognized by meteorologists, sometimes makes it physically possible for the insects to determine the direction of the wind from the nature of the buffeting they receive without sighting the ground. Apparently there are other times (when the temperature lapse rate is subadiabatic or when there is an actual temperature inversion) when the eddies of the wind give no clue to its main direction.

Locusts and some butterflies when migrating high above ground in a gusty wind have been observed to alter their body axes during a side gust so that their direction of movement relative to the ground (track) was kept constant by varying the direction of their flight through the air (course) (Williams, 1957). This 
TABLE 1. Reported observations of butterfly flights and their directions with respect to the wind (after Williams, 1958).

\begin{tabular}{|c|c|c|}
\hline & $\begin{array}{l}\text { Angle between } \\
\text { flight and wind }\end{array}$ & $\begin{array}{l}\text { Number of } \\
\text { records }\end{array}$ \\
\hline With the wind & $0^{\circ}$ & 84 \\
\hline Diagonally with the wind & $\begin{array}{l}+45^{\circ} \\
-45^{\circ}\end{array}$ & $\begin{array}{l}30 \\
19\end{array}$ \\
\hline Across the wind & $\begin{array}{l}+90^{\circ} \\
-90^{\circ}\end{array}$ & $\begin{array}{l}35 \\
34\end{array}$ \\
\hline Diagonally against the wind & $\begin{array}{l}+135^{\circ} \\
-135^{\circ}\end{array}$ & $\begin{array}{l}45 \\
33\end{array}$ \\
\hline Against the wind & $\pm 180^{\circ}$ & 87 \\
\hline
\end{tabular}

would indicate a definite means of orientation independent of any relation to the wind, and also of any image of the ground in the retina of the eyes unless the maximum compensatory height is higher than previously thought. Further evidence of an additional means of orientation is the fact that migrating butterflies and moths (Lepidoptera) have a sense of direction so strong they prefer to go over obstacles rather than around them (Williams, 1949). They are capable of maintaining their original direction by day or night, in sunny or cloudy weather, in dead calm or moderate winds, and in the tropics when the sun is directly overhead. There is even one instance of a continuous flight through fog. Williams (1958) lists the following additional means of orientation which have been reported or suggested:

Factors having a direction

Light from sun or moon (including plane of polarization of the light)

Earth's magnetic field (compass direction)

Factors having a gradient in a certain direction

Temperature

Humidity

Barometric pressure

Intensity of the earth's magnetic field

Corioli's effect due to earth's rotation

\section{Other factors}

Contours of the ground Scent

Jander (1963) discusses insect orientation in depth and provides many references. Lindauer (1967) expounds on the remarkable ability of bees to orient themselves.

There is no evidence of constant relation of flight to wind direction (Hocking, 1953). Williams (1958) tabulated 367 reported observations of butterflies (Lepidoptera) according to the angle between flight and wind, his results being reproduced in Table 1. Unfortunately, he did not specify the altitude of the flights, but it is assumed that most, if not all, observers were ground based. He suggested the large number of observations against the wind may have been due to greater observer interest in such cases. Williams emphasized his point with numerous figures of observed migratory Lepidoptera flights and their directions with respect to wind. $\mathrm{He}$ concluded that although more flights (or at least more observations of the flights) were against the wind, any angle was possible and even probable.

Butterflies on migration do not keep their bodies absolutely fixed in the direction of migratory movement as if kept in that position by a gyroscope (Williams, 1949, 1958). The body direction and even the direction of flight may alter from moment to moment owing to the buffeting of the wind, or by choice of the insect. However, insects, locusts in particular, have been observed to change direction of their air flight during lateral gusts of wind so as to allow for the gust and keep their track constant. Williams (1958), incidentally, questions the validity of the retinal image theory in such circumstances. Bees (Hymenoptera) have also been observed to make wind corrections in their flights to a preselected food source (Lindauer, 1967).

Detailed analysis of the track of locust swarms in relation to synoptic weather and of the flight of individuals within the swarms shows, contrary to superficial appearances and even with such strong fliers, that the swarm moves with the wind while the individuals within it fly in all directions (Johnson, 1965). In large flights the middle insects appear more oriented than those at the edge of the swarm (Williams, 1958). Schneider (1962) cited work which shows the outer insects tend to move into the main body. Locusts may thus head in one direction and move in another according to the resultant between the speed and direction of the wind and flight. In contrast with these reports, however, Williams' book (1958) contains a photograph of locust flight in which the individuals were astonishingly aligned. No altitude or wind direction was given. Observations have also been reported (Williams, 1958) in which the locusts near the ground flew against the wind while those $6 \mathrm{~m}$ above flew with it.

There is no evidence that migratory insects are blown passively without wing beat to extreme distances and it is doubtful if considerable distances are traversed unless the insects maintain themselves airborne by active flight (Johnson, 1965). However, it is known that some insects do occasionally passively ride the wind, In particular, locusts, aphids and leafhoppers allow themselves to be lifted by convection to avoid obstacles and pass out of range of any optomotor orienting effect of the ground pattern and ride the faster moving upper air (Kennedy, 1961; Schneider, 1962). Aphids are attracted upward by the short wavelengths of the sky radiation and then, since they are weak fliers, are passively transported on the winds aloft. Wing beat is only sufficient to overcome gravity. Their resultant downwind displacement is thus independent of orienta- 
TABLE 2. Observed and calculated insect flight speeds in $\mathrm{m} \mathrm{sec}^{-1}$ (after Hocking, 1953).

\begin{tabular}{|c|c|c|c|c|c|}
\hline \multirow[b]{2}{*}{ Species } & \multicolumn{3}{|c|}{ Continuous (cruising) speed } & \multicolumn{2}{|c|}{$\begin{array}{l}\text { Maximum speed over } \\
\text { short distances }\end{array}$} \\
\hline & $\begin{array}{l}\text { Observed } \\
\text { average }\end{array}$ & $\begin{array}{l}\text { Calculated } \\
\text { average }\end{array}$ & Maximum & Observed & Calculated \\
\hline $\begin{array}{l}\text { Stockflies (Diptera) } \\
\text { Tabanus affinis } \\
\text { Tabanus septentrionalis } \\
\text { Chrysops furcata } \\
\text { Chrysops nigripes }\end{array}$ & $\begin{array}{l}2.05 \\
2.69\end{array}$ & $\begin{array}{l}2.60 \\
2.75 \\
2.60\end{array}$ & $\begin{array}{l}3.75 \\
2.83\end{array}$ & $\begin{array}{l}6.58 \\
6.12\end{array}$ & $\begin{array}{l}6.42 \\
6.40 \\
5.85\end{array}$ \\
\hline $\begin{array}{l}\text { Mosquitoes (Diptera) } \\
\text { Aëdes campestris } \\
\text { Aëdes communis } \\
\text { Aëdes flavescens } \\
\text { Ä̈des nearcticus } \\
\text { Aëdes punctor }\end{array}$ & $\begin{array}{l}1.10^{*} \\
0.90\end{array}$ & $\begin{array}{l}0.75 \\
0.80 \\
\\
0.78\end{array}$ & $\begin{array}{l}1.59 \\
1.64\end{array}$ & $\begin{array}{l}2.52 \\
2.22\end{array}$ & $\begin{array}{l}2.20 \\
2.50\end{array}$ \\
\hline $\begin{array}{l}\text { Buffalo gnats or black flies (Diptera) } \\
\text { Simulium venustum } \\
\text { Simulium villatum }\end{array}$ & $\begin{array}{l}1.52 \\
2.48^{*}\end{array}$ & 1.65 & $\begin{array}{l}2.01 \\
2.71\end{array}$ & $\begin{array}{l}2.38 \\
2.95\end{array}$ & 2.45 \\
\hline $\begin{array}{l}\text { Honeybee (IIymenoptera) } \\
\text { Apis }\end{array}$ & 2.58 & & 3.52 & 4.18 & \\
\hline $\begin{array}{l}\text { Pomace fly or vinegar fly (Diptera) } \\
\text { Drosophila }\end{array}$ & 1.42 & & 1.78 & 1.81 & \\
\hline
\end{tabular}

* Based on only one specimen.

tion. A single insect, a locust for example, may use both active and passive flight.

With insects adapted to windborne travel, it can be assumed reasonably that when high in the air they fly unembarrassed by optomotor responses and, except when orienting to each other as in locust swarms, act independently within the air mass which carries them along (Johnson, 1965). Except for locusts, little is known about orientation at such heights although there are records of high flying butterflies drifting backward with the wind and going forward with it. In general, investigators studying large insects consider the direction of movement largely determined by the insect itself, while those studying smaller insects believe them to be directionalized by random wind movements (Hocking, 1953). The contribution which the wind may make to the dispersion of insects is potentially greater than that which the insects may make by their own efforts, however. Above the maximum compensatory height and above any height where winds are faster than a given insect can fly, displacement is mainly controlled by wind.

\section{Flight speeds of insects}

Estimates of the flight speeds of which insects are capable vary widely. Wind speed and direction information are seldom included in estimates of flight speed. This and the difficulty in accurately measuring the speed of free insects accounts for the diversity in reported observations. Hocking (1953) measures (by means of flight mills, a device used by entomologists to study speeds and durations of insect flights) and calculates (based on muscle weight) the average and maximum flight speeds of a number of insects. He also summarizes flight speed information on these insects published by other authors. He considers the most reliable observations those which limit the maximum speed of insect flight to about $16 \mathrm{~m} \mathrm{sec}^{-1}$ for short bursts and $12 \mathrm{~m} \mathrm{sec}^{-1}$ for continuous flight. Table 2 lists the measured and calculated speeds of flight for a number of insects and

TABLE 3. Summary of published information on the speed of flight $\left(\mathrm{m} \mathrm{sec}^{-1}\right)$ of insects related to the species studied (after Hocking, 1953).

\begin{tabular}{|c|c|}
\hline Species & Speed \\
\hline $\begin{array}{l}\text { Stockflies (Diplera) } \\
\text { Tabanus bovinus* } \\
\text { Tabanus bovinus* } \\
\text { Tabanus affinis } \\
\text { Tabanids }\end{array}$ & $\begin{array}{r}<14.00 \\
4.00 \\
<12.50 \\
>18.00\end{array}$ \\
\hline $\begin{array}{l}\text { Mosquitoes (Diplera) } \\
\text { Aëdes aegypti* } \\
\text { Aëdes aegypti* } \\
\text { Anopheles fuliginosus } \\
\text { Mansonia uniformis }\end{array}$ & $\begin{array}{l}1.50 \text { when forced by wind } \\
0.30-0.40 \text { otherwise } \\
0.08-0.33 \\
0.08-0.33\end{array}$ \\
\hline $\begin{array}{l}\text { Honeybee (Hymenoptera) } \\
\text { Apis workers } \\
\text { Apis workers } \\
\text { Apis workers } \\
\text { Apis workers } \\
\text { A pis workers } \\
\text { Apis workers } \\
\text { Apis workers } \\
\text { Apis workers } \\
\text { Apis workers } \\
\text { Apis drones }\end{array}$ & $\begin{array}{ll}\text { average } & 6.12 \\
\text { maximum } & 8.00 \\
\text { average } & 3.75 \\
\text { maximum } & 6.00 \\
\text { average } & 5.56 \\
\text { average } & 2.50 \\
\text { average } & 6.00 \\
\text { average } & 8.30 \text { unloaded } \\
\text { average } & 7.20 \text { full } \\
& 1.80\end{array}$ \\
\hline $\begin{array}{l}\text { Pomace fly or vinegar fly } \\
\text { (Diptera) Drosophila }\end{array}$ & 4.20 \\
\hline
\end{tabular}

* Different speeds are reported by different authors. 
TABLE 4. The range of flight and the endurance of the species studied (after Hocking, 1953).

\begin{tabular}{|c|c|c|c|c|}
\hline Species & $\begin{array}{l}\text { Calculated } \\
\text { maximum } \\
\text { range }(\mathrm{km})\end{array}$ & $\begin{array}{l}\text { Required } \\
\text { speed } \\
\left(\mathrm{m} \sec ^{-1}\right)\end{array}$ & $\begin{array}{c}\text { Range } \\
\text { from mill } \\
\text { data }(\mathrm{km})\end{array}$ & $\begin{array}{l}\text { Maximum } \\
\text { endurance } \\
\text { (hr) }\end{array}$ \\
\hline $\begin{array}{l}\text { Stockflies (Diptera) } \\
\text { Tabanus affinus } \\
\text { Tabanus septentrionalis } \\
\text { Chrryscps furcata } \\
\text { Chrysops nigripes }\end{array}$ & $\begin{array}{r}99 \\
102 \\
69 \\
76\end{array}$ & $\begin{array}{l}2.70 \\
2.50 \\
2.10 \\
2.10\end{array}$ & 91 & $\begin{array}{l}16 \\
17 \\
15 \\
16\end{array}$ \\
\hline $\begin{array}{l}\text { Mosquitoes (Diptera) } \\
\text { Ä̈des campestris } \\
\text { Ä̈des communis } \\
\text { Ä̈des nearcticus } \\
\text { Aëdes punctor }\end{array}$ & $\begin{array}{l}53 \\
22 \\
48 \\
46\end{array}$ & $\begin{array}{l}1.15 \\
1.20 \\
1.10 \\
1.20\end{array}$ & 40 & $\begin{array}{l}22 \\
72 \\
20\end{array}$ \\
\hline $\begin{array}{l}\text { Buffalo gnats or black flies } \\
\text { (Diptera) } \\
\text { Simulium venustum } \\
\text { Simulium vittatum }\end{array}$ & $\begin{array}{l}116 \\
104\end{array}$ & $\begin{array}{l}1.25 \\
1.15\end{array}$ & 102 & $\begin{array}{l}35 \\
34\end{array}$ \\
\hline $\begin{array}{l}\text { Honeybee (Hymensptera) } \\
\text { Apis }\end{array}$ & 46 & 2.50 & 44 & 7 \\
\hline $\begin{array}{l}\text { Pomace fly or vinegar fly } \\
\text { (Diptera) } \\
\text { Drosophila }\end{array}$ & 48 & 1.00 & 30 & 14 \\
\hline
\end{tabular}

Table 3 summarizes published information on the flight speeds of the same insects. Both tables are taken directly from Hocking's work. Kishaba et al. (1967) studied the cabbage looper moth (Trichoplusia ni, Hïbner) with a flight mill and found its maximum flight speed to be $2.7 \mathrm{~m} \mathrm{sec}^{-1}$ with an average of $1.36 \mathrm{~m} \mathrm{sec}^{-1}$. These speeds are not inconsistent with dot angel velocities if one also considers the high winds at altitudes.

\section{Flight altitudes of insects}

Although insects apparently prefer to remain near the ground, they have been detected in the air as far as the eye can see (Williams, 1949, 1957, 1958). A butterfly (Danaus plexippus) prefers heights of more than $100 \mathrm{~m}$ for migration. Another butterfly (Ascia monüste) has been reported by airplane observers to heights of more than $1000 \mathrm{~m}$. Monarch butterflies, in large numbers, have been detected flying at altitudes beyond that at which they were visible to the unaided eye. There is evidence that butterflies may fly higher when the wind is behind them and lower with a head wind. Locusts have also been observed at high altitudes. Swarms have been reported by aircraft observers more than $2100 \mathrm{~m}$ above ground. Glick (Moulton, 1942) reports on the concentrations of insects up to $1500 \mathrm{~m}$. He also found spiders (Class: Arachnida, Order: Araneida) and webs at elevations up to $13,500 \mathrm{~m}$. Others report insects observed at heights up to $13,000 \mathrm{~m}$. In addition to these elevations above ground, numerous observations of butterflies active in the Himalayas have been reported (Williams, 1958) including Vanessa cardui at $5200 \mathrm{~m}$ and Aglais cashmerensis at $5500 \mathrm{~m}$. No heights above ground were given for these. In brief, insects are possible at the altitudes of dot angel observations.

\section{Flight ranges of insects}

Flight ranges of which some insects are capable are given in Table 4, the data being taken from the work of
Hocking (1953). He considers the maximum range of any insect unable to feed while flying to be $1000 \mathrm{~km}$. Migration studies have indicated locust flights of 2400 $\mathrm{km}$, butterfly flights of $2400 \mathrm{~km}$ (Danaus plexippus), and other butterfly flights of $4800 \mathrm{~km}$ (Williams, 1957). There are records of flights of dragonflies (Odonata) longer than $800 \mathrm{~km}$. Kishaba et al. (1967) found flight distance capabilities up to $196 \mathrm{~km}$ for the cabbage looper moths they tested in the laboratory.

Table 4 also includes the maximum endurance (hours in flight) for the insects studied. A butterfly, Danaus plexippus, is estimated to be able to fly $117 \mathrm{hr}$ on its initial fuel supply (Johnson, 1965). It probably has the greatest endurance of all insects. Locusts are known to be able to fly for $60 \mathrm{hr}$. The moths studied by Kishaba et al. (1967) flew continuously up to $7 \mathrm{hr}$. With endurances like these, insects certainly remain as possible sources for angels tracked as long as $\mathbf{3 5} \mathrm{min}$.

\section{Insect density in the atmosphere}

Migration occurs regularly in locusts, dragonflies, butterflies, moths, some bugs (Heteroptera), some beetles (Coleoptera, especially the ladybird beetles, i.e., the Coccinellidae), and some flies (Diptera, particularly the family containing syrphid, flower, sweat, hover, and drone flies, i.e., the Syrphidae) (Williams, 1957, 1958). The density may be thick, as in swarms, or it may be so thin each participant is hundreds of meters from its nearest companion. The migration may or may not be seasonal and may or may not be related to weather. It may be by day, night, or both, and over land or sea. Although insects usually migrate with others of their own species, cases have been reported of two species migrating together. An interesting comment of Hocking's (1953) is that two insects (of the same species) flew better in flight mill tests than one. That is, when two insects were flying together, their ranges and endurances were longer. If insects are the source of dot angels, this could offer one explanation for the echo oscillations characteristic of multiple body scattering. Taylor (1967) indicated that the density of (nonmigrating) insects in the air was related to the weather.

\section{Summary}

It does not seem likely that one could predict the orientation of an insect in flight at altitudes at which dot angel echoes have been observed. Insects are known to fly with, against, or at an angle to the prevailing wind. Insects may actively fly to keep themselves airborne, may simply ride the moving air, or both. Consequently, the polarization dependence of insect orientation offers little hope of positively identifying insects as the source of dot angel echoes.

Speeds at which insects are capable of flying and the measured wind speeds at dot angel echo altitudes are consistent with radar observation of dot angel echo movement. 
Altitudes at which insects have been found in flight agree with altitudes at which dot angel echoes are normally found.

Endurance of insects in flight can easily account for the relatively long times that dot angels have been tracked.

Although the polarization characteristics of the insect body does not appear to be a usable way of identifying insects as dot angel echoes, insects must remain as prime candidates for the source of these echoes.

Acknowledgments. The research reported in this paper was sponsored by the National Science Foundation under Grants GP 2596 and GA 772.

\section{REFERENCES}

Daykin, P. N., 1967 : Orientation of Aëdes aegypti in vertical air currents. Can. Entomol., 99, 303-308.

Glover, K. M., K. R. Hardy, T. G. Konrad, W. N. Sullivan and A. S. Michaels, 1966: Radar observations of insects in free flight. Science, 154, 967-972.

Hajovsky, R. G., A. P. Deam and A. H. LaGrone, 1966: Radar reflections from insects in the lower atmosphere. IEEE Trans. Antennas and Propagation, AP-14, 224-227.

Hocking, B., 1953: The intrinsic range and speed of flight of insects. Trans. Roy. Entomol. Soc. London, E104, 223-345.

Jander, R., 1963: Insect orientation. Annual Review of Entomology, Vol. 8, Palo Alto, Calif., Annual Reviews, Inc., 95-114.

Johnson, C. G., 1965: Migration. The Physiology of Insecta, Vol. 2, New York, Academic Press, 188-226.
Kennedy, J. S., 1940: The visual responses of flying mosquitoes. Proc. Zool. Soc. London, 109, 221-242.

- - 1951: The migration of the desert locust. Phil. Trans. Roy. Soc. London, B235, 163-290.

- 1961: A turning point in the study of insect migration. Nature, 189, 785-791.

Kishaba, A. N., T. J. Henneberry, P. J. Hancock and H. H. Toba, 1967 : Laboratory technique for studying flight of cabbage looper moths and the effects of age, sex, food, and tepa on flight characteristics. J. Econ. Entomol., 60, 359-366.

Lindauer, M., 1967: Recent advances in bee communication and orientation. Annual Review of Entomology, Vol. 12, Palo Alto, Calif., Annual Reviews, Inc., 439-470.

Markl, H., and M. Lindauer, 1965: Physiology of insect behavior. The Physiology of Insecta, Vol. 2, New York, Academic Press, 3-123.

Moulton, F. R., 1942: Aerobiology. American Association for the Advancement of Science, Publ. No. 17, p. 49.

Pruess, K. P., and N. C. Pruess, 1966: Note on a Malaise trap for determining flight directions of insects. $J$. Kansas Entomol. Soc., 39, 98-102.

Schneider, F., 1962: Dispersal and migration. Annual Review of Entomology, Vol. 7, Palo Alto, Calif., Annual Reviews, Inc., 223-241.

Taylor, L. R., 1967: The mode of action of weather on insect flight. Biometeorology, Vol. 2, Oxford, Pergamon Press Symp. Publ., 579-582.

Williams, C. B., 1949: Migration in Lepidoptera and the problem of orientation. Proc. Roy. Entomol. Soc. London, C13, 17-84.

- 1957 : Insect migration. Annual Review of Entomology, Vol. 2, Palo Alto, Calif., Annual Reviews, Inc., 163-180.

- 1958: Insect Migration. New York, The Macmillian Co., $235 \mathrm{pp}$. 